Article

\title{
Influencing Factors of Motion Responses for Large-Diameter Tripod Bucket Foundation
}

\author{
Xianqing Liu ${ }^{1,2} \mathbb{C}$, Puyang Zhang ${ }^{2, *}$, Mingjie Zhao ${ }^{1}$, Hongyan Ding ${ }^{2}$ and Conghuan Le ${ }^{2} \mathbb{C}$ \\ 1 National Engineering Research Center for Inland Waterway Regulation, Chongqing Jiaotong University, \\ Chongqing 400074, China; liuxianqing_1986@126.com (X.L.); m.j.zhao@163.com (M.Z.) \\ 2 State Key Laboratory of Hydraulic Engineering Simulation and Safety, Tianjin University, Tianjin 300072, \\ China; dhy_td@163.com (H.D.); leconghuan@163.com (C.L.) \\ * Correspondence: zpy@tju.edu.cn; Tel.: +86-2740-0842
}

Received: 24 September 2019; Accepted: 13 November 2019; Published: 18 November 2019

\begin{abstract}
Large-diameter multi-bucket foundation is well suited for offshore wind turbines at deeper water than $20 \mathrm{~m}$. Air floating transportation is one of the key technologies for the cost-effective development of bucket foundation. To predict the dynamic behavior of large-diameter tripod bucket foundation (LDTBF) supported by an air cushion and a water plug inside every bucket in waves, three 1/25-scale physical model tests with different bucket spacing were conducted in waves; detailed prototype foundation models were established using a hydrodynamic software MOSES with a draft of $4.0 \mathrm{~m}, 4.5 \mathrm{~m}$, and $5.0 \mathrm{~m}$ and with a water depth of $10.0 \mathrm{~m}, 11.25 \mathrm{~m}$, and $12.5 \mathrm{~m}$. The numerical and experimental results are consistent for heaving motion, while exhibiting favorable agreement for pitching motion. The results show that the resonant periods for heaving motion increased with increasing draft and water depth. The maximum amplitude for heaving motion first decreased and then increased with the increase of water depth and spacing between the buckets. The maximum amplitude for pitching motion first decreased and then increased with increasing water depth but decreased with increasing spacing between the buckets. The wider the spacing between the bucket foundations, the larger the heave response amplitude operators (RAOs). Simply improving the pitch RAOs by increasing the spacing between bucket foundations is limited and negatively affects motion performance during the transportation of LDTBF.
\end{abstract}

Keywords: offshore wind turbine; large-diameter tripod bucket foundation; air floating; response amplitude operator; resonant period

\section{Introduction}

With the continuous development of offshore wind power, diverse foundations, such as gravity foundation, pile foundation, tripod foundation, jacket foundation, and even floating foundation, have been evaluated as the foundation of offshore wind turbines (OWTs) [1,2]. In recent years, bucket foundation has attracted much attention because of its easy construction, convenient transportation, reusability, and good soil applicability. Furthermore, the cost of piling operation can be saved and noise pollution during piling can be avoided. A single bucket with a large diameter or multi-bucket foundations combining several bucket foundations in a regular polygon shape are a potential alternative foundation to improve the bearing capacities of foundations for OWTs.

Figure 1 shows the three main types of bucket foundation applied to the engineering practices of OWTs [3-7]. A mono bucket foundation (e.g., developed by the Universal Foundation) was applied to the Frederikshavn wind farm in Denmark in 2002; it was used as the foundation of meteorological mast at the Horns Rev2 in Denmark in March 2009 and the Dogger Bank in the UK in September 2012. A suction bucket jacket (SBJ) (developed by DONG Energy) was installed at the 
Borkum Riffgrund 1 offshore wind farm in Germany in October 2014. A mono bucket with multi compartments (jointly developed by Tianjin University and Daoda Company) was installed in Qidong city. Moreover, a composite bucket foundation (CBF) was used with one-step transportation and installation technology in Sanxia Xiangshui and Dafeng offshore wind farm in China.

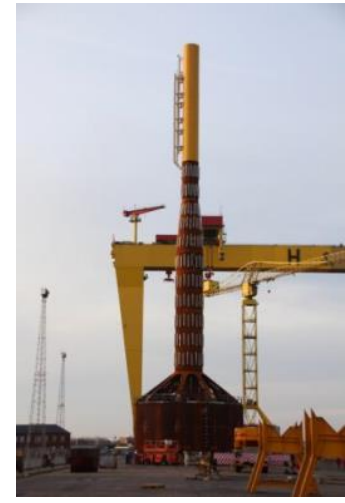

(a)

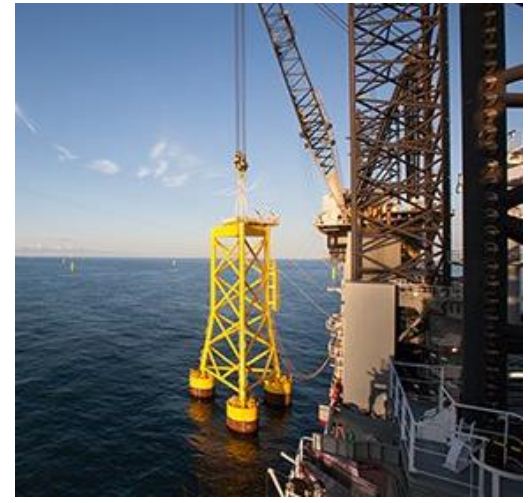

(b)

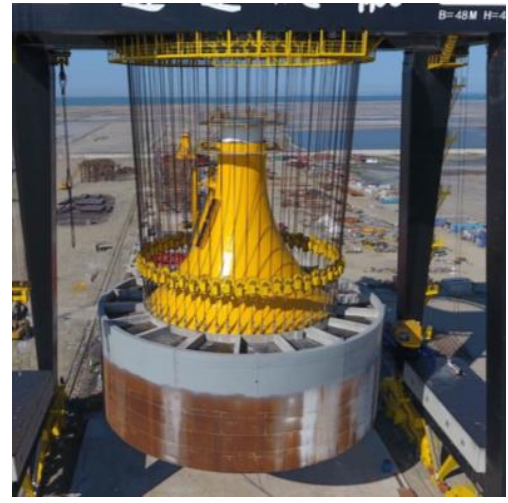

(c)

Figure 1. Offshore wind turbines (OWTs) with different types of bucket foundations: (a) Monobucket foundation, (b) suction bucket jacket (SBJ), (c) composite bucket foundation (CBF) with multi compartments.

For the mono bucket foundation with several compartments or multi-bucket foundation, air floating technology can be used to transport the structure from the dock to the construction site. This is one of the key technologies for the cost-effective development of bucket foundation for OWTs, as shown in Figure 2. The key scientific issues related air floating are the interactions between marine environment, construction loads, and structure. Because of open bottom and air compressibility, the air floating characteristics and mechanics of bucket foundation are different from those of conventional rigid bottom float. An ordinary floating body is equivalent to a structure with the foundation supported on a water spring. On the other hand, bucket foundation is equivalent to a structure with a flexible foundation supported on a series of springs coupled with compressible air spring and water spring [8-14]. Therefore, to predict the air floating performance of bucket foundations accurately, it is incorrect to use the same parameters and calculation methods used in predicting the hydrodynamic performance and response of traditional rigid bottom platforms or ship structures.

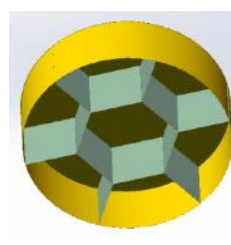

(a)

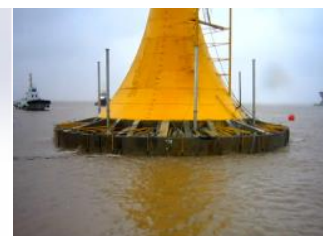

(b)

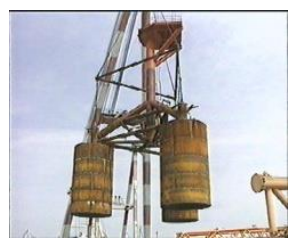

(c)

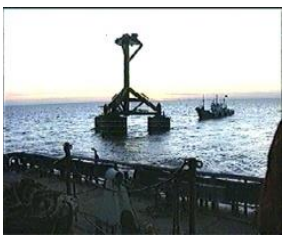

(d)

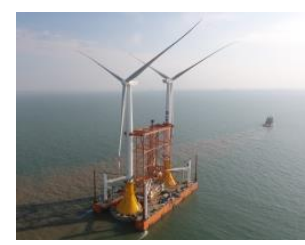

(e)

Figure 2. Transportation of bucket foundation: (a) Monobucket with seven rooms as air cushions, (b) self-floating towing, (c) multibucket foundation, (d) air floating towing, (e) one-step transportation and installation technology.

In recent years, studies on air-cushion-supported structures mainly focused on the hydrostatic and hydrodynamic characteristics of structures. In the hydrostatic aspect, based on the perfect air law, Seidl introduced an air-pocket factor to describe the relationship between the compressibility of trapped air and the resulting hydrostatic stiffness of the system [15]. By considering the air floating structure as a single freedom rigid body and spring system, Bie et al. developed an air floating reducing coefficient, 
accounting for the difference in the restoring force coefficient between the air floating structures and the conventional buoy. The basic mass in the motion equation should include both the mass of the structure and the mass of the water plug inside the buoy, where the added mass coefficient of heaving is 1.2 [8]. Thiagarajan et al. showed that the introduction of an air cushion support into a concrete gravity structure (CGS) increases the pitch response, while slightly affecting the heaving motion [12]. Chenu et al. experimentally evaluated the effect of water plug height and compartmentalization of an air cushion on the metacentric height, heave, and pitch natural frequency and the added mass of an air-cushion-supported box model. The air cushion reduced the stability of vessel and influenced both the natural frequency and added mass in heaving and pitching [16]. Thiagarajan developed a correction formula for the metacentric height incorporating the net effect of an air cushion on the static stability of a compartmented structure [17]. Kessel presented a non-dimensional parameter that considers the compressibility factor of an air cushion. The parameter can be used to correct the heave, roll, and pitch restoring coefficients [18].

In the hydrodynamic aspect, using the three-dimensional diffraction-radiation theory, Pinkster et al. studied the motion of structures both partially and completely supported by air cushions in waves [19-21]. The results are consistent with those of Tabeta's model test [22]. Malenica and Zalar extended Pinkster's method and calculated and analyzed the hydrodynamic coefficients of the heaving motion of an air cushion support structure [23]. Using the boundary integral equation method, Gueret and Hermans extended Malenica's and Zalar's work and analyzed the hydrodynamic coefficients and internal free surface changes of an air-cushion-supported structure at zero speed in regular waves [24]. Using the three-dimensional potential flow theory and linearized adiabatic law, Kessel and Pinkster calculated the motion responses and wave loads of a rectangular barge with partial buoyancy provided by an air cushion in waves. The effects of different forms of subdivision on the motions and loads of structure were evaluated by comparing with the results of model tests $[25,26]$. Using a $1 / 20$-scale physical model and hydrodynamic software MOSES, Le et al. experimentally evaluated the effect of towing speed, water depth, free-board height, and wave direction on the air floating towing behavior of a multibucket foundation platform [27]. Using MOSES, Zhang et al. studied the hydrodynamic motion of self-floating towing for a large prestressed concrete bucket foundation (LPCBF) [7]. The hydrodynamic response of large floater with an air cushion not only depends on the wave conditions but also on the mass of water column, the height of the air cushion, and air pressure distribution. Using MOSES and physical model experiments, Zhang et al. developed a one-step integrated transportation and installation technique to minimize the offshore operation and maximize the proportion of work carried out onshore with cost, quality, and safety benefits. The dynamic and kinematic characteristics for the transportation system with different drafts and air pressures in the bucket were obtained. A smaller draft and a larger air cushion contribute to safe transportation [7].

In the design stage, OWTs with a large power rate should be installed at deeper water than $20 \mathrm{~m}$ and subjected to strong horizontal and moment loadings by the wind, wave, and current [28]. Therefore, the large-diameter multi-bucket foundation (LDMBF) is well suited for OWTs at deeper water. The wave diffraction and hydrodynamic interactions between bucket foundations are more complex with increasing diameters of the bucket during air floating transportation. Although previous studies explained the draft, compartments, water depth, and wave effect on the motion of air-cushion-supported structures, the motion response of large-diameter tripod bucket foundations (LDTBFs) has been rarely studied. This study aimed to predict the hydrodynamic motion response of LDTBFs with an air cushion used to support each bucket foundation. The response amplitude operators (RAOs) of LDTBF with different sizes under given conditions were experimentally evaluated. The experimental results were compared with the simulation results obtained using MOSES to evaluate the motion characteristics of heave and pitch of LDTBF, mainly to analyze the effect of draught, water depth, and spacing between bucket foundations. 


\section{Theoretical Formulation}

As shown in Figure 3, the local coordinate system oxyz was used. The origin of coordinate is located at the center of top of bucket. The positive directions of the $o x$ axis and the $o z$ axis are right and upward, respectively. The oy axis is determined using the corkscrew rule. The diameter of bucket foundation is $D$. Because the bucket foundation is a thin-walled structure, the effect of thickness on the characteristics of bucket foundation can be neglected. The cross-sectional area of foundation is $A$; the height is $H$; the draft is $H_{d}$; the height of freeboard is $H_{f}$; the structural mass is $M_{s}$. The difference of water head between the external and interior water surface is $H_{w}$; the height of the air column in the bucket is $H_{a}$. The atmospheric pressure outside the bucket is $P_{a}$. The weight $G_{s}$ and pressure $P_{b}$ at the internal air-water interface can be expressed as follows $[7,16]$ :

$$
\begin{gathered}
G_{s}=M_{s} \cdot g \\
P_{b}=\rho_{w} \cdot g \cdot H_{w}+P_{a} \\
F_{b}=\rho_{w} \cdot g \cdot H_{w} \cdot A
\end{gathered}
$$

where $\rho_{w}$ is the density of water; $g$ is the acceleration due to gravity; $F_{b}$ is buoyancy with the coordinates of floating center at $\left(0,0,-H_{w} / 2\right)$.

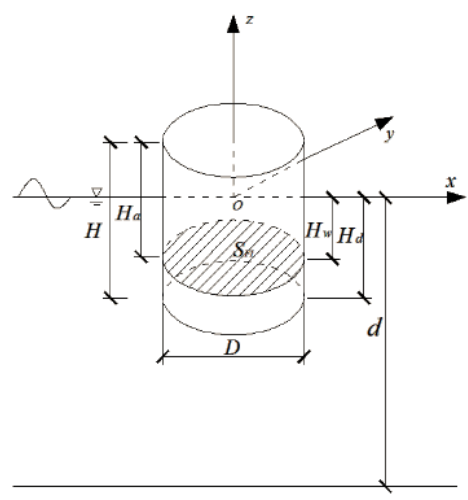

Figure 3. Schematic diagram of the floating state for a single bucket foundation.

\section{Experimental Setup and Test Procedures}

\subsection{Physical Model}

The geometric details of LDMBF prototypes and the models used in the experiments are shown in Figure 4. As shown in Figure $4 a-c$, all the prototypes are composed of three bucket foundations with the same diameter of $10 \mathrm{~m}$ and the same height $6.75 \mathrm{~m}$ and an equilateral triangle connecting frame used to constrain the foundations into a whole. The side lengths are $15 \mathrm{~m}$ (equal to 1.5 times the diameter D) for Prototype 1 (Figure 4a), $20 \mathrm{~m}$ (equal to 2.0 times the diameter D) for Prototype 2 (Figure $4 \mathrm{~b}$ ), and $25 \mathrm{~m}$ (equal to 2.5 times the diameter D) for Prototype 3 (Figure 4c). Three corresponding 1/25-scale stainless steel models were fabricated according to geometric similarity and Froude number similarity. With a $2.0 \mathrm{~mm}$-thick side wall and $1.0 \mathrm{~mm}$-thick top lid, the diameter, height, and mass of every bucket foundation are $0.4 \mathrm{~m}, 0.25 \mathrm{~m}$, and $5.85 \mathrm{~kg}$, respectively. The weights of the connecting frame welded by stainless steel pipes are $1.2 \mathrm{~kg}$ for Model 1 (Figure 4d), $1.4 \mathrm{~kg}$ for Model 2 (Figure 4e), and $1.7 \mathrm{~kg}$ for Model 3 (Figure 4f). 

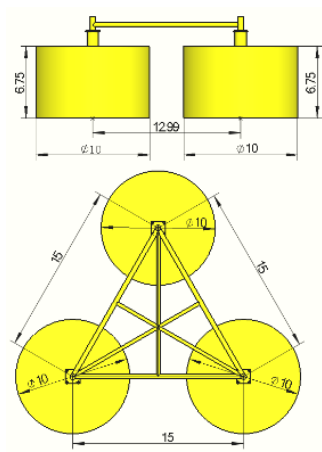

(a)

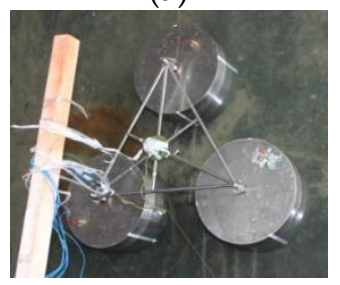

(d)
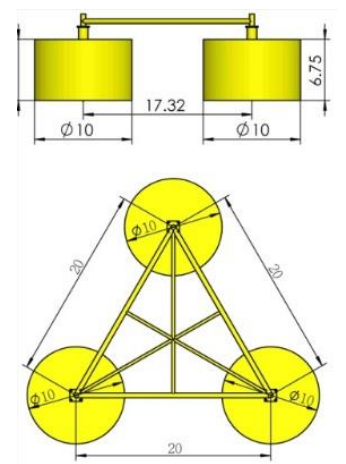

(b)

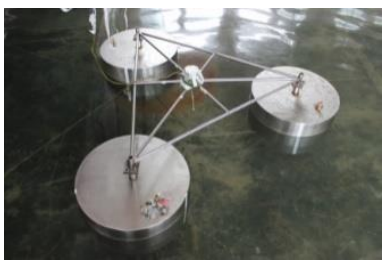

(e)
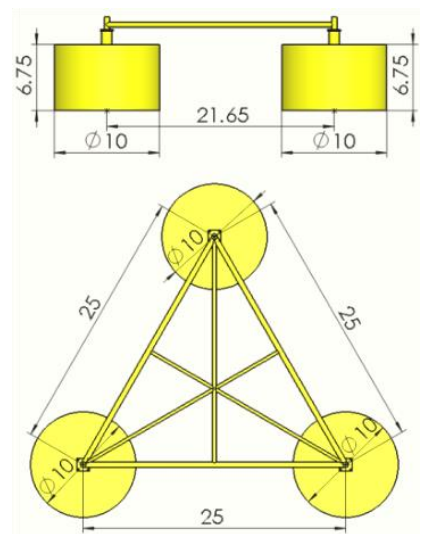

(c)

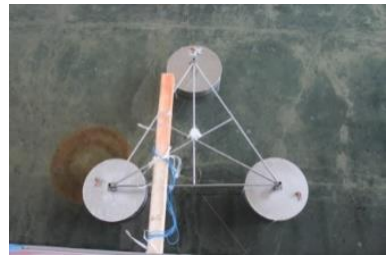

(f)

Figure 4. Prototypes and physical models of large-diameter multi-bucket foundation (LDMBF): (a) Prototype 1 with a distance of $1.5 \mathrm{D}$ between one bucket and another bucket, (b) Prototype 2 with a distance of 2.0 D between one bucket and another bucket, (c) Prototype 3 with a distance of $2.5 \mathrm{D}$ between one bucket and another bucket, (d) Laboratory model 1 for Prototype 1, (e) Laboratory model 2 for Prototype 2, (f) Laboratory model 3 for Prototype 3.

As shown in Figure 5, the origin $O$ of the global coordinate system is located at the bottom of structure. The origin $O$ is located at the centroid at the bottom of the structure. The positive direction of the $O X$ axis, perpendicular to the line connecting the gravity center of $2 \#$ and $3 \#$ bucket foundations, is the direction of incident wave and surge motion. The positive direction of $O Z$ is set vertically upward and the direction of the heave motion. The $O Y$ axis, the direction of the sway motion, is defined by the corkscrew rule. Tables 1-3 show the pertinent parameters of Prototype 1 and Model 1, Prototype 2 and Model 2, and Prototype 3 and Model 3 in the design and experiments with different drafts, respectively.

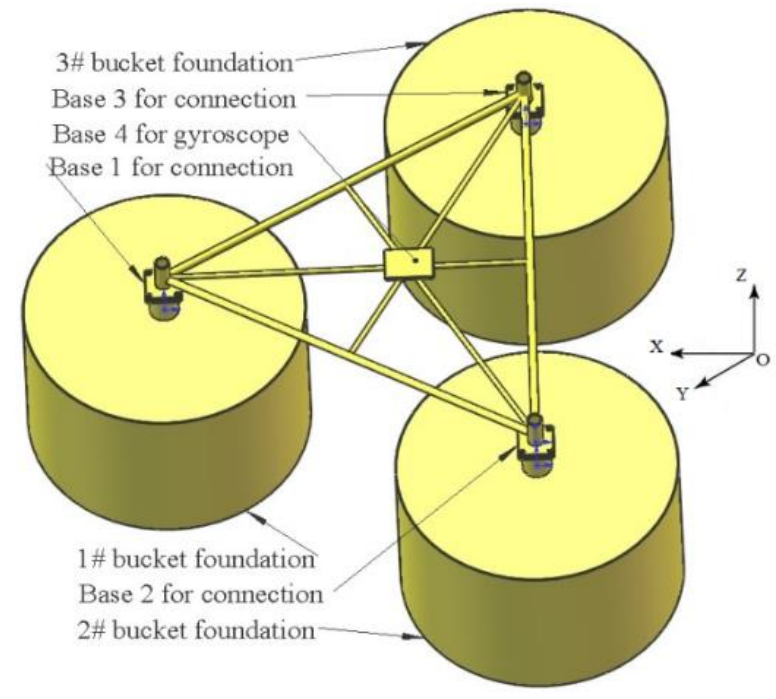

Figure 5. Composition of LDTBF. 
Table 1. Details of the parameters of Prototype 1 and Model 1 evaluated in the experiments.

\begin{tabular}{|c|c|c|c|c|c|c|c|c|c|}
\hline \multirow{2}{*}{ Items } & \multirow{2}{*}{$D(\mathrm{~m})$} & \multirow{2}{*}{$H(\mathrm{~m})$} & \multirow{2}{*}{$\begin{array}{l}H_{d} \\
(\mathrm{~m})\end{array}$} & \multirow{2}{*}{$S(m)$} & \multirow{2}{*}{$\begin{array}{l}M_{s} \\
(\mathbf{k g})\end{array}$} & \multirow{2}{*}{$M_{s}+M_{w}(\mathrm{~kg})$} & \multicolumn{2}{|c|}{ Moment of Inertia $\left(\mathrm{kg} \cdot \mathrm{m}^{4}\right)$} & \multirow{2}{*}{$\begin{array}{c}\text { Gravity Center of } \\
\text { Structure Above } O(\mathrm{~m})\end{array}$} \\
\hline & & & & & & & $I_{b m X}$ & $I_{b m Y}$ & \\
\hline Model 1 & 0.4 & 0.25 & 0.16 & 0.6 & 18.75 & 61.83 & 4.691 & 4.697 & $(0,0,0.156)$ \\
\hline Prototype 1 & 10 & 6.75 & 4.0 & 15.0 & 292.97 & 966.1 & $45.81 \times 10^{6}$ & $45.87 \times 10^{6}$ & $(0,0,3.89)$ \\
\hline Model 1 & 0.4 & 0.25 & 0.18 & 0.6 & 18.75 & 69.56 & 5.311 & 5.317 & $(0,0,0.156)$ \\
\hline Prototype 1 & 10 & 6.75 & 4.5 & 15.0 & 292.97 & 1086.9 & $51.87 \times 10^{6}$ & $51.92 \times 10^{6}$ & $(0,0,3.89)$ \\
\hline Model 1 & 0.4 & 0.25 & 0.20 & 0.6 & 18.75 & 77.28 & 5.967 & 5.972 & $(0,0,0.156)$ \\
\hline Prototype 1 & 10 & 6.75 & 5.0 & 15.0 & 292.97 & 1207.6 & $58.27 \times 10^{6}$ & $58.32 \times 10^{6}$ & $(0,0,3.89)$ \\
\hline
\end{tabular}

Table 2. Details of the parameters of Prototype 2 and Model 2 evaluated in the experiments.

\begin{tabular}{|c|c|c|c|c|c|c|c|c|c|}
\hline \multirow{2}{*}{ Items } & \multirow{2}{*}{$D(\mathrm{~m})$} & \multirow{2}{*}{$H(\mathrm{~m})$} & \multirow{2}{*}{$\begin{array}{l}H_{d} \\
(\mathrm{~m})\end{array}$} & \multirow{2}{*}{$S(m)$} & \multirow{2}{*}{$\begin{array}{l}M_{s} \\
(\mathbf{k g})\end{array}$} & \multirow{2}{*}{$M_{s}+M_{w}(\mathrm{~kg})$} & \multicolumn{2}{|c|}{ Moment of Inertia $\left(\mathrm{kg} \cdot \mathrm{m}^{4}\right)$} & \multirow{2}{*}{$\begin{array}{c}\text { Gravity Center of } \\
\text { Structure Above } O(\mathrm{~m})\end{array}$} \\
\hline & & & & & & & $I_{b m X}$ & $I_{b m Y}$ & \\
\hline Model 1 & 0.4 & 0.25 & 0.16 & 0.8 & 18.95 & 61.83 & 7.518 & 7.529 & $(0,0,0.156)$ \\
\hline Prototype 1 & 10 & 6.75 & 4.0 & 20.0 & 296.09 & 966.1 & $73.42 \times 10^{6}$ & $72.53 \times 10^{6}$ & $(0,0,3.89)$ \\
\hline Model 1 & 0.4 & 0.25 & 0.18 & 0.8 & 18.95 & 69.56 & 8.498 & 8.51 & $(0,0,0.156)$ \\
\hline Prototype 1 & 10 & 6.75 & 4.5 & 20.0 & 296.09 & 1086.9 & $82.99 \times 10^{6}$ & $83.11 \times 10^{6}$ & $(0,0,3.89)$ \\
\hline Model 1 & 0.4 & 0.25 & 0.20 & 0.8 & 18.95 & 77.28 & 9.514 & 9.525 & $(0,0,0.156)$ \\
\hline Prototype 1 & 10 & 6.75 & 5.0 & 20.0 & 296.09 & 1207.6 & $92.91 \times 10^{6}$ & $93.02 \times 10^{6}$ & $(0,0,3.89)$ \\
\hline
\end{tabular}

Table 3. Details of the parameters of Prototype 3 and Model 3 evaluated in the experiments.

\begin{tabular}{|c|c|c|c|c|c|c|c|c|c|}
\hline \multirow{2}{*}{ Items } & \multirow{2}{*}{$D(\mathrm{~m})$} & \multirow{2}{*}{$H(\mathrm{~m})$} & \multirow{2}{*}{$\begin{array}{l}H_{d} \\
(\mathrm{~m})\end{array}$} & \multirow{2}{*}{$S(m)$} & \multirow{2}{*}{$\begin{array}{l}M_{s} \\
(\mathbf{k g})\end{array}$} & \multirow{2}{*}{$M_{s}+M_{w}(\mathrm{~kg})$} & \multicolumn{2}{|c|}{ Moment of Inertia $\left(\mathrm{kg} \cdot \mathrm{m}^{4}\right)$} & \multirow{2}{*}{$\begin{array}{c}\text { Gravity Center of } \\
\text { Structure Above } O(\mathrm{~m})\end{array}$} \\
\hline & & & & & & & $I_{b m X}$ & $I_{b m Y}$ & \\
\hline Model 1 & 0.4 & 0.25 & 0.16 & 1.0 & 19.25 & 61.83 & 11.126 & 11.147 & $(0,0,0.156)$ \\
\hline Prototype 1 & 10.0 & 6.75 & 4.0 & 25.0 & 300.78 & 966.1 & $108.65 \times 10^{6}$ & $108.86 \times 10^{6}$ & $(0,0,3.89)$ \\
\hline Model 1 & 0.4 & 0.25 & 0.18 & 1.0 & 19.25 & 69.56 & 12.57 & 12.59 & $(0,0,0.156)$ \\
\hline Prototype 1 & 10.0 & 6.75 & 4.5 & 25.0 & 300.78 & 1086.9 & $122.75 \times 10^{6}$ & $122.95 \times 10^{6}$ & $(0,0,3.89)$ \\
\hline Model 1 & 0.4 & 0.25 & 0.20 & 1.0 & 19.25 & 77.28 & 14.05 & 14.071 & $(0,0,0.156)$ \\
\hline Prototype 1 & 10.0 & 6.75 & 5.0 & 25.0 & 300.78 & 1207.6 & $137.21 \times 10^{6}$ & $137.41 \times 10^{6}$ & $(0,0,3.89)$ \\
\hline
\end{tabular}




\subsection{Experimental Setup}

The experiments were conducted in the harbor basin at the National Engineering Research Center for Inland Waterway Regulation of Chongqing Jiaotong University in China. The dimensions of the basin are $30 \mathrm{~m}$ long, $20 \mathrm{~m}$ wide, and $1.2 \mathrm{~m}$ deep. A plate-type wave maker driven by an electronic-hydraulic servo system was installed at one end of the basin; a wave-absorbing equipment was fixed at the other end to eliminate the effect of wave reflection. Regular and irregular waves with a period of $0.5-5 \mathrm{~s}$, wave height of $0.02-0.25 \mathrm{~m}$, and a maximum water depth of $0.8 \mathrm{~m}$ can be generated by the experimental facility.

A schematic of the experimental setup is shown in Figure 6. The LDMBF structure, supported by the positive pressure of interior air relative to the outside atmosphere pressure, was placed on the water surface at a distance of $10 \mathrm{~m}$ from the wave maker. To limit the structure within a certain range of motion without affecting the wave-frequency motion, the model was anchored using a horizontally placed soft-spring arrangement at the bow and stern [21].

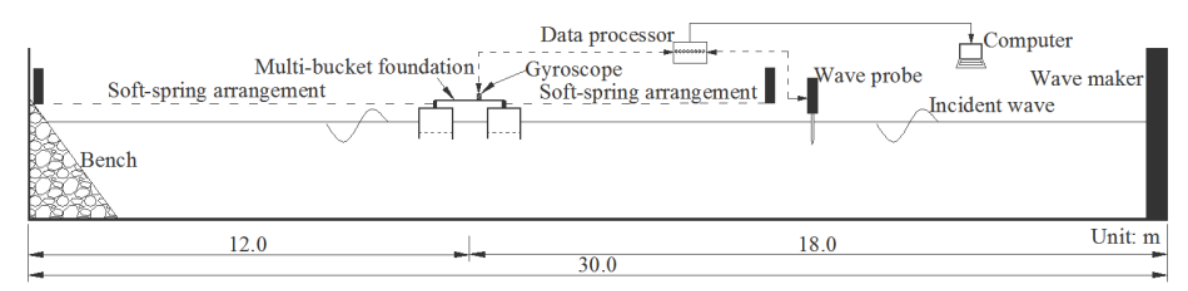

Figure 6. Sketch of the experiment setup for multibucket foundation.

As shown in Figure 7, combined with the several calibration bars attached to the side-wall surface of bucket foundation, an exhaust valve to transfer air inside and outside of the structure was fixed on the top cover of each bucket foundation to adjust the draught.

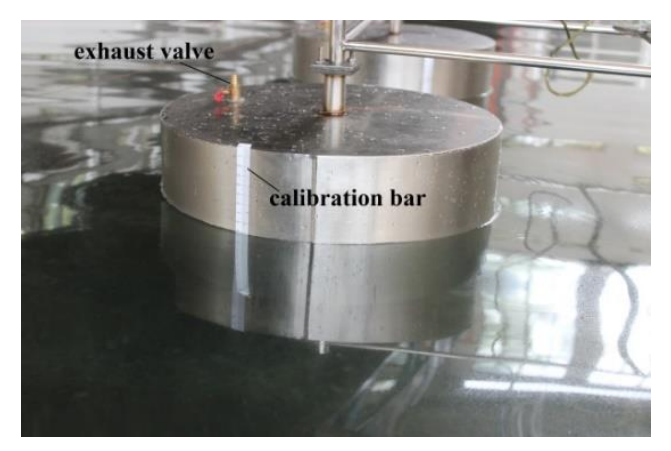

Figure 7. Model of a single bucket foundation.

The experimental data reported by Thiagarajan et al. show different wave amplitudes in heave and pitch RAO. No significant difference was observed between the wave amplitudes of $8 \mathrm{~mm}$ and $20 \mathrm{~mm}$, thus concluding that the system is linear within the range of wave amplitudes tests [13]. Because the target geometry scale factor in this study is $1 / 25$, the scales for wave height and water depth are also $1 / 25$, and the scale for the wave period is $1 / 5$. The wave height in the laboratory tests was fixed at $0.08 \mathrm{~m}$. The model wave period was in the range 1.0-3.0 s, while the prototype wave period was 5.0-15.0 s, within the range of most wave periods for wind-generated waves. In ship dynamics, the magnification factor of oscillating motion of a ship in waves is not only related to the inherent characteristics of the structure and frequency of wave disturbing forces or moments, but also to the ratio of the wavelength (L) to the length of the ship [29-31]. In this study, the outermost distance from one bucket to the other, $\mathrm{S}$, was selected to compare the test results. All the wave conditions tested in the experiment are listed in Table 4. The normalized L/S varied from 1.15 to 6.96. The three water 
depths are $0.40 \mathrm{~m}, 0.45 \mathrm{~m}$, and $0.50 \mathrm{~m}$ with $0.18 \mathrm{~m}$ draft. Three drafts of $0.16 \mathrm{~m}, 0.18 \mathrm{~m}$, and $0.20 \mathrm{~m}$ with $0.5 \mathrm{~m}$ water depth were evaluated in this study.

Table 4. Experimental test conditions.

\begin{tabular}{cccccc}
\hline \multirow{2}{*}{$\boldsymbol{d}(\mathrm{m})$} & \multirow{2}{*}{ Period (s) } & \multirow{2}{*}{ (m) } & \multicolumn{3}{c}{ L/S } \\
\cline { 4 - 6 } & & & Model 1 & Model 2 & Model 3 \\
\hline 0.40 & $1.0-3.0$ & $1.46-5.76$ & $1.59-6.26$ & $1.34-5.27$ & $1.15-4.55$ \\
0.45 & $1.0-3.0$ & $1.49-6.09$ & $1.62-6.62$ & $1.36-5.57$ & $1.18-4.81$ \\
0.50 & $1.0-3.0$ & $1.51-6.4$ & $1.64-6.96$ & $1.38-5.86$ & $1.19-5.06$ \\
\hline
\end{tabular}

\subsection{Data Acquisition and Processing}

A CS-VG-02A vertical gyroscope was placed on Base 4 to evaluate the motion behavior of LDTBFs. To avoid the adverse effects of sensor contact with water during tests, a steel tube with a diameter of $1.0 \mathrm{~m}$ and height of $1.25 \mathrm{~m}$ was fixed at the top of each bucket foundation (Figure 5). The data of wave height in each test were acquired using a wave probe. The data of motion were obtained at 200 samples per second using a serial port assistant and post-processed using Fourier analysis to recover the amplitude and phase information using MATLAB software.

\section{Numerical Simulation in MOSES}

The numerical models were established using MOSES to predict the dynamic behavior of LDTBF supported by an air cushion and a water plug inside each bucket foundation in waves, as shown in Figure 8a-c [32]. The three-dimensional diffraction theory was used to accurately predict the three-dimensional dynamic behaviors of flexible air floating structures of arbitrary shapes under the marine environment. A concept of "interior compartment with holes" was introduced to deal with the contents (air and water) inside each bucket foundation. During modeling, a flood valve or vent valve can be opened to allow water run into the compartment. The internal gauge pressure, i.e., air pressure in the compartment minus atmospheric pressure, is set by the opening and closing the control valves. The pertinent parameters in simulation for Prototypes 1, 2, and 3 are shown in Tables 5-7, respectively.

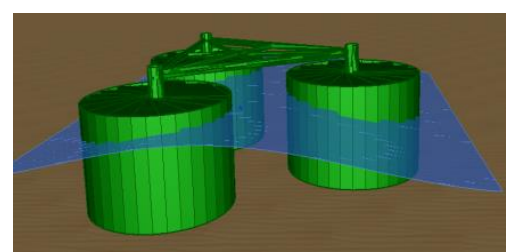

(a)

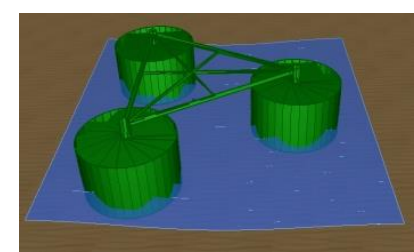

(b)

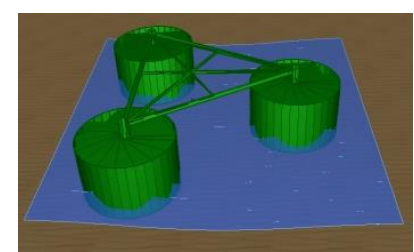

(c)

Figure 8. Hydrodynamic models of LDTBF in MOSES: (a) Simulated model 1 for Prototype 1, (b) Simulated model 2 for Prototype 2, and (c) Simulated model 3 for Prototype 3.

Table 5. Details of the parameters for the numerical simulations of prototype 1 in MOSES.

\begin{tabular}{cccccc}
\hline $\boldsymbol{H}_{\boldsymbol{d}} \mathbf{( k g )}$ & $\boldsymbol{M}_{\boldsymbol{s}}(\mathbf{k g})$ & $\boldsymbol{M}_{\boldsymbol{s}}+\boldsymbol{M}_{\boldsymbol{w}} \mathbf{( k g )}$ & External Head $(\mathbf{m})$ & Interior Head $(\mathbf{m})$ & Pressure Head $(\mathbf{m})$ \\
\hline 4.0 & 292.97 & 960.35 & 4.0 & 2.82 & 1.21 \\
4.5 & 292.97 & 1080.47 & 4.5 & 3.32 & 1.21 \\
5.0 & 292.97 & 1200.6 & 5.0 & 3.83 & 1.21 \\
\hline
\end{tabular}


Table 6. Details of the parameters for the numerical simulations of prototype 2 in MOSES.

\begin{tabular}{cccccc}
\hline $\boldsymbol{H}_{\boldsymbol{d}}(\mathbf{k g})$ & $\boldsymbol{M}_{\boldsymbol{s}}(\mathbf{k g})$ & $\boldsymbol{M}_{\boldsymbol{s}}+\boldsymbol{M}_{\boldsymbol{w}} \mathbf{( k g )}$ & External Head $(\mathbf{m})$ & Interior Head $(\mathbf{m})$ & Pressure Head $(\mathbf{m})$ \\
\hline 4.0 & 296.09 & 960.51 & 4.0 & 2.80 & 1.23 \\
4.5 & 296.09 & 1080.64 & 4.5 & 3.31 & 1.23 \\
5.0 & 296.09 & 1200.77 & 5.0 & 3.82 & 1.23 \\
\hline
\end{tabular}

Table 7. Details of the parameters for the numerical simulations of prototype 3 in MOSES.

\begin{tabular}{cccccc}
\hline $\boldsymbol{H}_{\boldsymbol{d}}(\mathbf{k g})$ & $\boldsymbol{M}_{\boldsymbol{s}}(\mathbf{k g})$ & $\boldsymbol{M}_{\boldsymbol{s}}+\boldsymbol{M}_{\boldsymbol{w}}(\mathbf{k g})$ & External Head $(\mathbf{m})$ & Interior Head $(\mathbf{m})$ & Pressure Head $(\mathbf{m})$ \\
\hline 4.0 & 300.78 & 960.75 & 4.0 & 2.78 & 1.25 \\
4.5 & 300.78 & 1080.89 & 4.5 & 3.29 & 1.25 \\
5.0 & 300.78 & 1201.02 & 5.0 & 3.80 & 1.25 \\
\hline
\end{tabular}

\section{Results and Discussion}

In Section 3, the similarity scale for the models of the prototypes of LDTBF is based on geometric similarity and gravity similarity. The similarity ratio of translational accelerations in surge, sway, and heave motions and the rotational angles in roll, pitch, and yaw motions are all 1/1. Furthermore, LDTBF is usually transported to the installation site with 1\# bucket in front, 2\# and 3\# buckets in rear in practical operation [33]. The safer transportation and construction are guaranteed by the better motion response characteristics of heave and pitch under the coupled marine environmental loads. The maximum amplitudes of heave translation $\left(\mathrm{M}_{\text {heave }}\right)$ and pitch rotation $\left(\mathrm{M}_{\text {pitch }}\right)$ of LDTBF were obtained from the test data and the wave amplitudes $\left(\mathrm{H}_{\mathrm{i}}\right)$ for each period were measured using the wave gauges. The heave and pitch RAOs are defined as $\mathrm{M}_{\text {heave }} / \mathrm{H}_{\mathrm{i}}$ and $\mathrm{M}_{\text {pitch }} / \mathrm{H}_{\mathrm{i}}$, respectively. For comparison with MOSES results; all the graphs for RAOs are shown at the prototype scale.

The comparisons of RAOs for heave acceleration and pitch angle between the experimental tests and MOSES numerical simulations for Model 1, Model 2, and Model 3 at a $10.0 \mathrm{~m}$ water depth and $4.5 \mathrm{~m}$ draught conditions are shown in Figure 9. The maximum amplitudes occurred in the vicinity of natural periods of heave and pitch motions. The experimental and simulated results in the heaving direction are consistent, while the results in the pitching direction agree very well irrespective of the trend or values, i.e., the air floating hydrodynamics characteristics of LDTBF in the waves can be treated as a three-dimensional scattering problem based on the linear potential theory. Further theoretical analysis for LDTBF can be strengthened in this aspect.

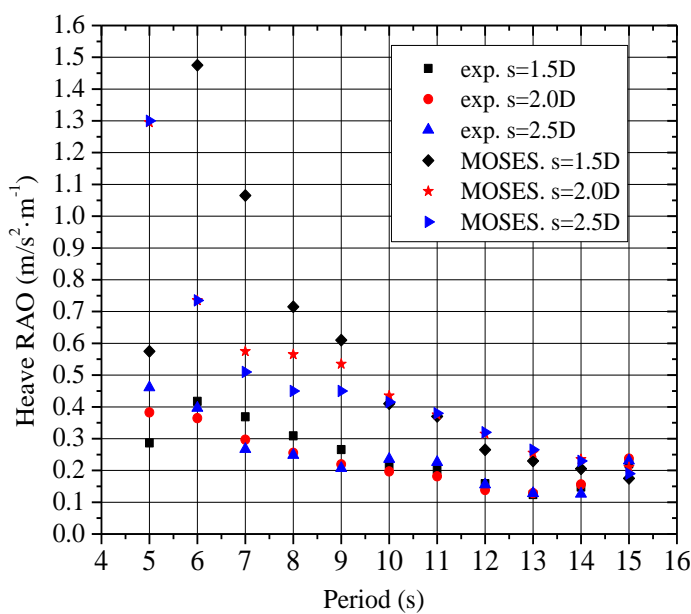

(a)

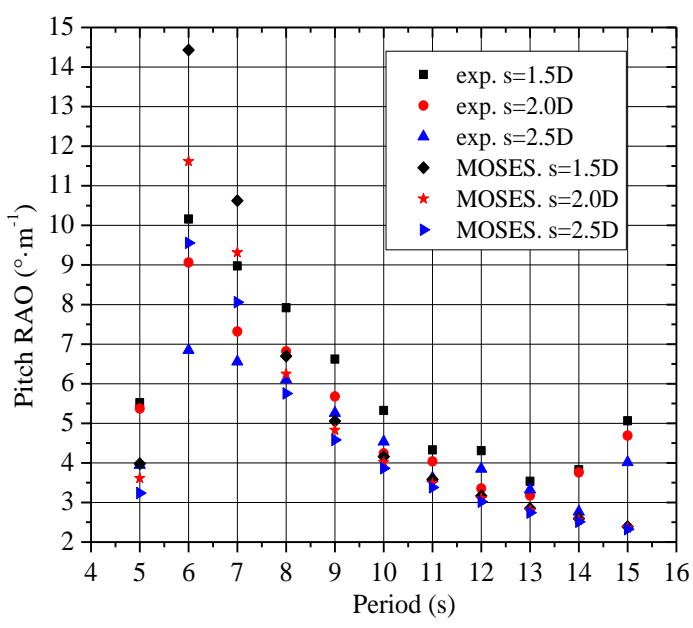

(b)

Figure 9. Experimental and simulated RAOs for Model 1, Model 2, and Model 3: (a) heave RAO and (b) pitch RAO. 


\subsection{Effect of Draft}

From the perspective of the structure's own performance, as shown in Tables 1-3, the bucket foundations used in laboratory tests have the same diameter and weight; no large difference is observed in the weights of connecting frames. Therefore, the masses of Model 1, Model 2, and Model 3 involved in the oscillating motions are basically identical under the same draught. However, the mass and moment of inertia increase with increasing draught in the case of the same model, and the moment of initial significantly increases with increasing spacing of bucket foundation under the same draught. Tables 4-6 show that the pressure heads in each bucket, provided by the difference of heads between external heads outside the bucket and interior heads inside the bucket, supported the weight of LDTBF. The relationship between pressure head and weight of structure is positive. From the perspectives of wave-induced loads on structure, the forces and motion responses of LDTBF are inevitably affected with the increase in draft, the increase in the distance between the structure and the seabed and the surface area of the wave action and the reduction of the gravity center. Figures 10-12 show the motion performances of Model 1, Model 2, and Model 3 with different drafts.

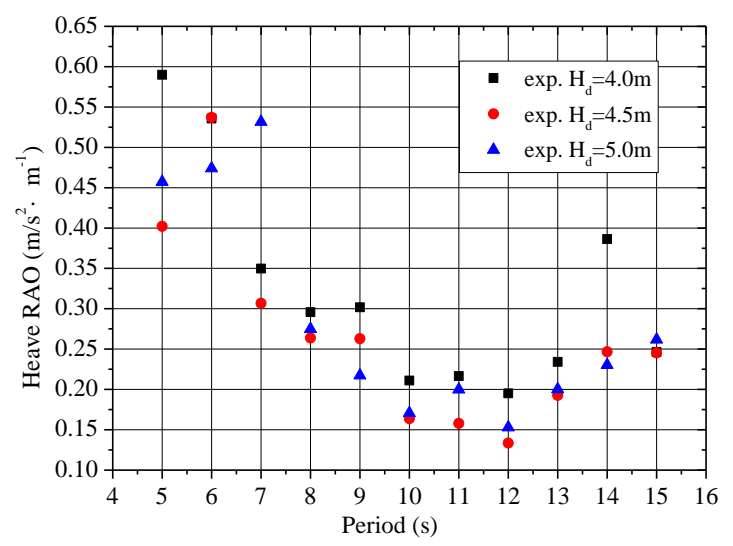

(a)

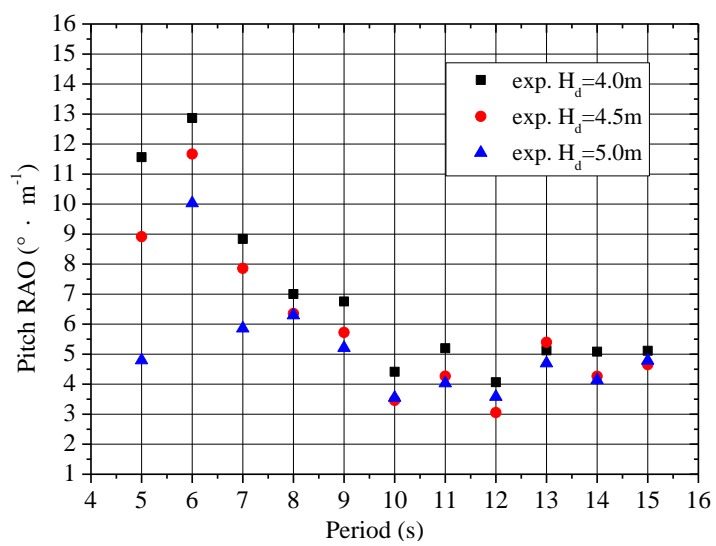

(b)

Figure 10. Experimental RAOs for Model 1 with different drafts: (a) heave RAO and (b) pitch RAO.

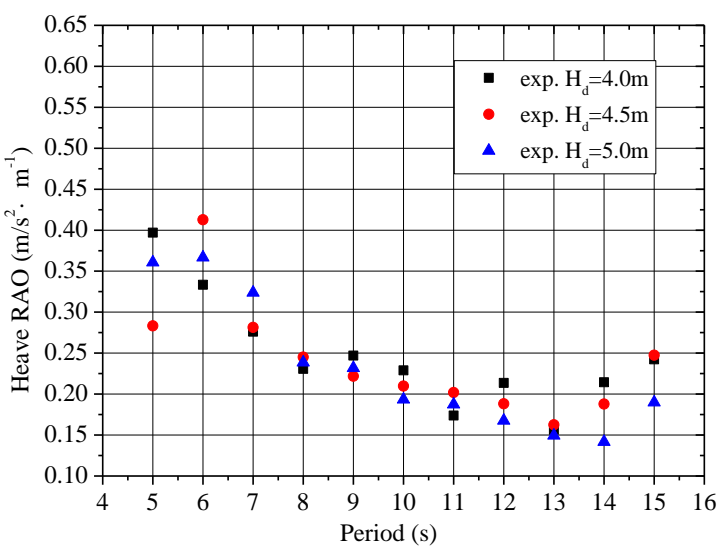

(a)

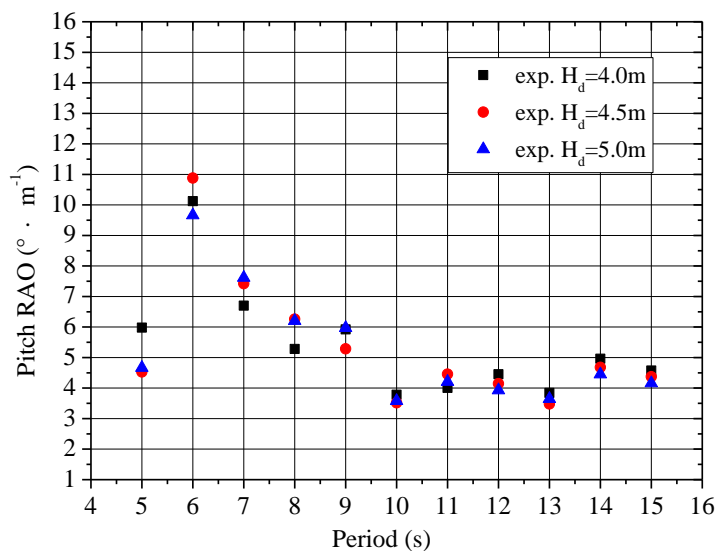

(b)

Figure 11. Experimental RAOs for Model 2 with different drafts: (a) heave RAO and (b) pitch RAO. 


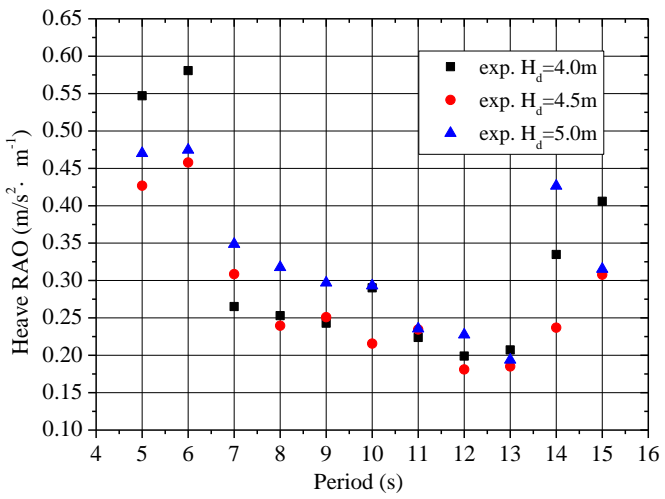

(a)

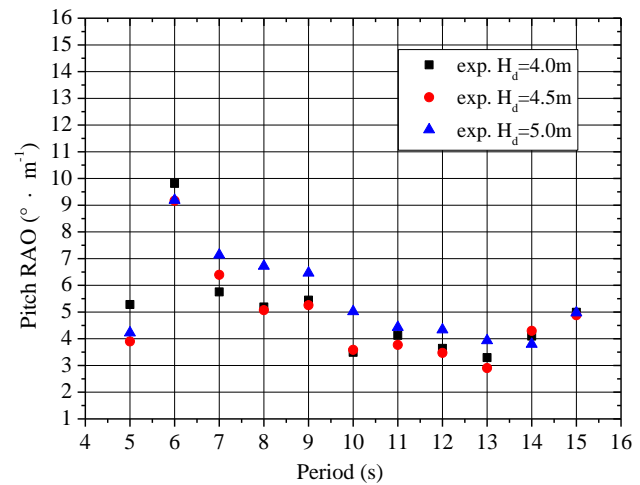

(b)

Figure 12. Experimental RAOs for Model 3 with different drafts: (a) heave RAO and (b) pitch RAO.

The RAOs of heave acceleration for Model 1 with different drafts at a constant $12.5 \mathrm{~m}$ water depth are shown in Figure 10a. The maximum amplitudes of heave acceleration $0.59 \mathrm{~m} / \mathrm{s}^{2}$ at a $4.0 \mathrm{~m}$ draft, $0.54 \mathrm{~m} / \mathrm{s}^{2}$ at a $4.5 \mathrm{~m} \mathrm{draft}$, and $0.53 \mathrm{~m} / \mathrm{s}^{2}$ at a $5.0 \mathrm{~m}$ draft occurred near the period of $5 \mathrm{~s}, 6 \mathrm{~s}$, and $7 \mathrm{~s}$, respectively, i.e., the resonant periods of heaving motion increased with increasing draft, while the motion responses decreased with the increase in draft. When the period was longer than $7 \mathrm{~s}$, the amplitudes of heave acceleration first decreased and then increased slightly with increasing draft. The larger the wave period, the more significant the trend. The heave acceleration at a $4.5 \mathrm{~m}$ draft is almost smaller in most periods.

The RAOs of pitch angle for Model 1 with different drafts at a constant $12.5 \mathrm{~m}$ water depth are shown in Figure 10b. The maximum amplitudes of pitch angle appearing near the period of $6 \mathrm{~s}$ were $12.9^{\circ}$ at a $4.0 \mathrm{~m}$ draft, $11.7^{\circ}$ at a $4.5 \mathrm{~m}$ draft, and $10.0^{\circ}$ at a $5.0 \mathrm{~m}$ draft. The pitch responses decreased with increasing draft and especially had a significant trend when the period was less than $9 \mathrm{~s}$. When the period was longer than $9 \mathrm{~s}$, the pitch angles varied from $4^{\circ}$ to $5^{\circ}$.

The RAOs of heave acceleration for Model 2 with different drafts at a constant $12.5 \mathrm{~m}$ water depth are shown in Figure 11a. The maximum amplitudes of heave acceleration, $0.397 \mathrm{~m} / \mathrm{s}^{2}$ at a $4.0 \mathrm{~m}$ draft, $0.41 \mathrm{~m} / \mathrm{s}^{2}$ at a $4.5 \mathrm{~m} \mathrm{draft}$, and $0.36 \mathrm{~m} / \mathrm{s}^{2}$ at a $5.0 \mathrm{~m}$ draft, occurred near the period of $5 \mathrm{~s}, 6 \mathrm{~s}$, and $6 \mathrm{~s}$, respectively. The resonant periods of heaving motion increased with increasing draft, while the motion responses first increased and then decreased with the increase in draft. The amplitudes of heave acceleration decreased with increasing draft when the period was greater than $7 \mathrm{~s}$. With a longer period, the heave RAOs were almost constant at $0.2 \mathrm{~m} / \mathrm{s}^{2}$.

The RAOs of pitch angle for Model 2 with different drafts at a constant $12.5 \mathrm{~m}$ water depth are shown in Figure 11b. The maximum amplitudes of pitch angle appearing near the period of $6 \mathrm{~s}$ were $10.12^{\circ}$ at a $4.0 \mathrm{~m} \mathrm{draft}, 10.88^{\circ}$ at a $4.5 \mathrm{~m} \mathrm{draft}$, and $9.66^{\circ}$ at a $5.0 \mathrm{~m}$ draft, respectively. The pitch responses first increased and then decreased with the increase in draft. The amplitude change for pitch angles of 5-9 s around the resonant period is significantly larger than that of 9-15 s. With a longer period, the RAOs of pitch angles were almost constant at $4.0^{\circ}$.

The RAOs of heave acceleration for Model 3 with different drafts at a constant $12.5 \mathrm{~m}$ water depth are shown in Figure 12a. The maximum amplitudes of heave acceleration, $0.58 \mathrm{~m} / \mathrm{s}^{2}$ at a $4.0 \mathrm{~m}$ draft, $0.46 \mathrm{~m} / \mathrm{s}^{2}$ at a $4.5 \mathrm{~m}$ draft, and $0.47 \mathrm{~m} / \mathrm{s}^{2}$ at a $5.0 \mathrm{~m}$ draft, all occurred near the period of $6 \mathrm{~s}$. The responses of heave acceleration first decreased and then increased with the increase in draft. Outside the range of the resonant period, the responses of heave acceleration with a draft of $5.0 \mathrm{~m}$ are significantly larger than those of $4.0 \mathrm{~m}$ and $4.5 \mathrm{~m}$ draft, whereas the responses of heave acceleration at $4.5 \mathrm{~m}$ draft are almost the smallest in all periods.

The RAOs of pitch angle for Model 3 with different drafts at a constant $12.5 \mathrm{~m}$ water depth are shown in Figure 12b. The period for amplitudes of pitch angle occurred at $6 \mathrm{~s}$ with different drafts. With increasing draft from $4.0 \mathrm{~m}$ to $4.5 \mathrm{~m}$, the maximum value of pitch RAO decreased from $9.82^{\circ}$ to 
$9.17^{\circ}$. However, the maximum value of pitch RAO only increased by $0.02^{\circ}$ when the draft increased from $4.5 \mathrm{~m}$ to $5.0 \mathrm{~m}$. The pitch angles at $4.5 \mathrm{~m}$ draft are almost smaller than those of other drafts in most periods.

\subsection{Effect of Water Depth}

In ship structures, the vertical planar motion (heave and pitch) of a structure is enhanced in shallow water [12,34-36]. The water depth from seabed to wave surface did not change in space and time during the transportation of LDTBF. During the towing of structures from deep water to shallow water, the wavelength becomes shorter, the wave velocity becomes slower, and the clearance between the bottoms of LDTBF to the seabed becomes smaller. The gravity center sinks due to the blocking effect of ocean fluid, equivalent to adding an increment to the draft of structure. During the towing of structure from shallow water to deep water, the wave exciting forces acting on the structure also change with a larger wavelength and a faster wave velocity. Figures 13-15 show the motion performances of Model 1, Model 2, and Model 3 with different water depths.

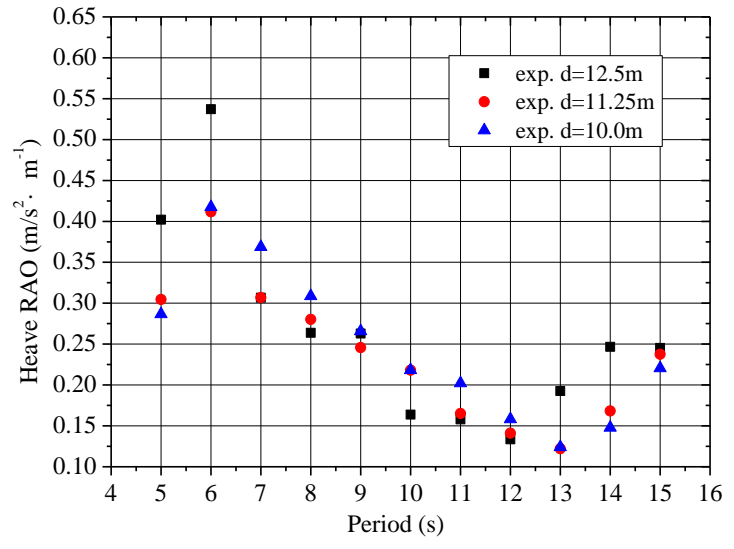

(a)

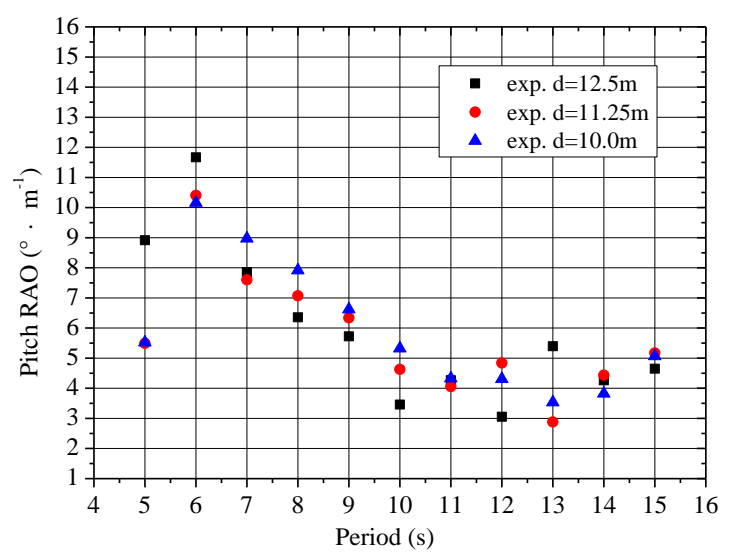

(b)

Figure 13. Experimental RAOs for Model 1 with different water depths: (a) heave RAO and (b) pitch RAO.

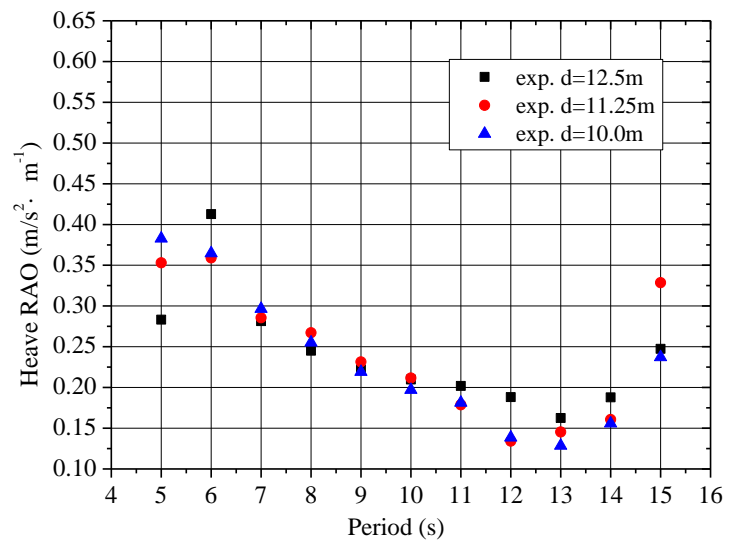

(a)

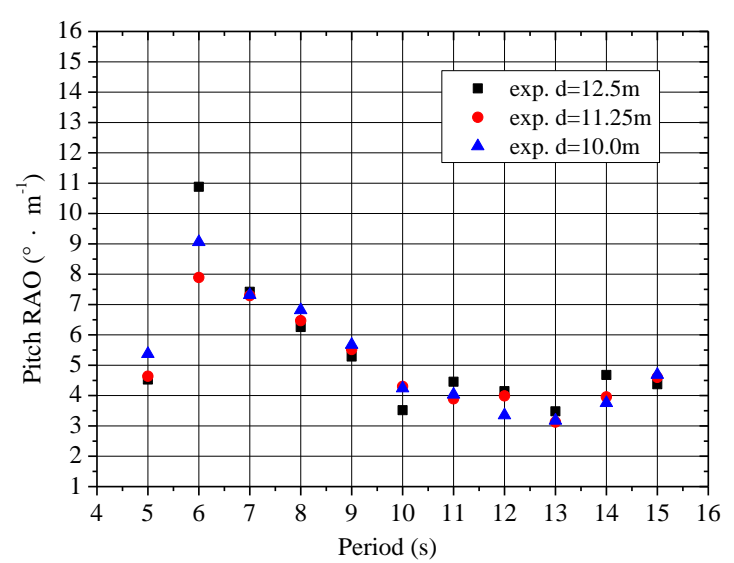

(b)

Figure 14. Experimental RAOs for Model 2 with different water depths: (a) heave RAO and (b) pitch RAO. 


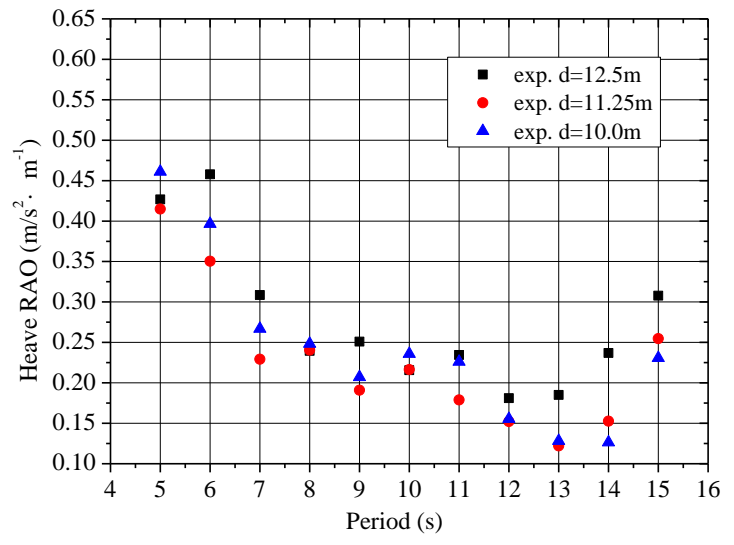

(a)

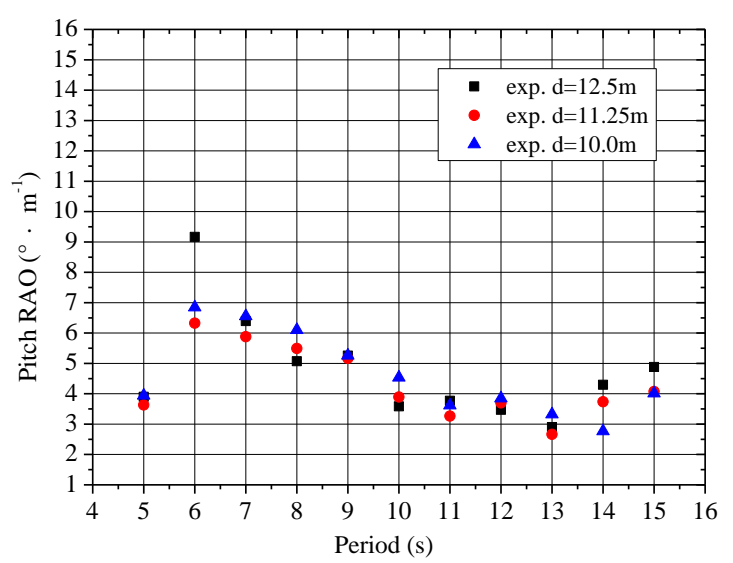

(b)

Figure 15. Experimental RAOs for Model 1 with different water depths: (a) heave RAO and (b) pitch RAO.

The RAOs of heave acceleration and pitch angle for Model 1 with different water depths at $4.5 \mathrm{~m}$ draft are shown in Figure 13. The maximum amplitudes of heave acceleration and pitch angle, $0.537 \mathrm{~m} / \mathrm{s}^{2}$ and $11.67^{\circ}$ at a $12.5 \mathrm{~m}$ water depth, $0.46 \mathrm{~m} / \mathrm{s}^{2}$ and $10.41^{\circ}$ at a $11.25 \mathrm{~m}$ water depth, and $0.47 \mathrm{~m} / \mathrm{s}^{2}$ and $10.41^{\circ}$ at a $10.0 \mathrm{~m}$ water depth, all occurred near the period of $6 \mathrm{~s}$. It is shown that an increase in the water depth reduced the heave and pitch motion slightly with a shallower water depth of less than $11.25 \mathrm{~m}$. The RAOs of heave acceleration increased with the increase in water depth with the period less than $6 \mathrm{~s}$ and larger than $13 \mathrm{~s}$ and decreased in the other periods. The RAOs of pitch angle show a similar decrease with increasing water depth at almost the entire range of the period. With a longer period, the RAOs of pitch angle were almost constant at $4.5^{\circ}$.

The RAOs of heave acceleration and pitch angle for Model 2 with different water depths at $4.5 \mathrm{~m}$ draft are shown in Figure 14. Only several periods significantly affect the RAOs of heave acceleration and pitch angle. They are $5 \mathrm{~s}, 6 \mathrm{~s}$, and $15 \mathrm{~s}$ for heave motion and $5 \mathrm{~s}, 6 \mathrm{~s}$, and $10 \mathrm{~s}$ for pitch motion. The maximum amplitudes of motion in heave and pitch first decreased and then increased with increasing water depth. The resonant period for heave motion decreased from $6 \mathrm{~s}$ to $5 \mathrm{~s}$ with a shallower water depth. This can be attributed to the added draft resulting from the blocking effect of ocean fluid. There is a positive influence on the mass involved in heaving vibration due to the added draft, decreasing the resonant period.

The RAOs of heave acceleration and pitch angle for Model 3 with different water depths at $4.5 \mathrm{~m}$ draft are shown in Figure 15. In Figure 15a, the maximum amplitudes of heave acceleration, $0.461 \mathrm{~m} / \mathrm{s}^{2}$ at a $12.5 \mathrm{~m}$ water depth, $0.415 \mathrm{~m} / \mathrm{s}^{2}$ at a $11.25 \mathrm{~m}$ water depth, and $0.457 \mathrm{~m} / \mathrm{s}^{2}$ at a $10.0 \mathrm{~m}$ water depth, occurred near the period of $5 \mathrm{~s}, 5 \mathrm{~s}$, and $6 \mathrm{~s}$, respectively. The periods of maximum values of heave acceleration increased with increasing water depth. The amplitudes of heave acceleration at $11.25 \mathrm{~m}$ water depth are less than those of other water depths in most periods. In Figure 15b, a comparison of pitch RAOs with different water depths shows that an increase in the water depth slightly decreased the pitch angle. However, the maximum values of pitch RAO increased from $6.84^{\circ}$ to $9.17^{\circ}$ with the increase in water depth from $10.0 \mathrm{~m}$ to $12.5 \mathrm{~m}$. A sharp fluctuation occurred around the resonant period. The reason for the fluctuation in pitch RAO can be attributed to the well-known shallow water effect: the shallower the water depth, the slower the heave and pitch motion.

\subsection{Effect of Spacing between Bucket Foundations}

As shown in Tables 1-3, the moment of inertia of LDTBF, one of the key factors affecting the pitch motion, increases with increasing spacing between bucket foundations. In Table 4, the ratio of wavelength to spacing of structures is inversely proportional to the spacing and the motion responses for LDTBF are inevitably changed in waves with the coupled variations of wave exciting forces caused 
by the hydrodynamic interaction between bucket and the structure's own performance. Figures 16-18 show the motion performances of Model 1, Model 2, and Model 3 with different spacings between the bucket foundations.

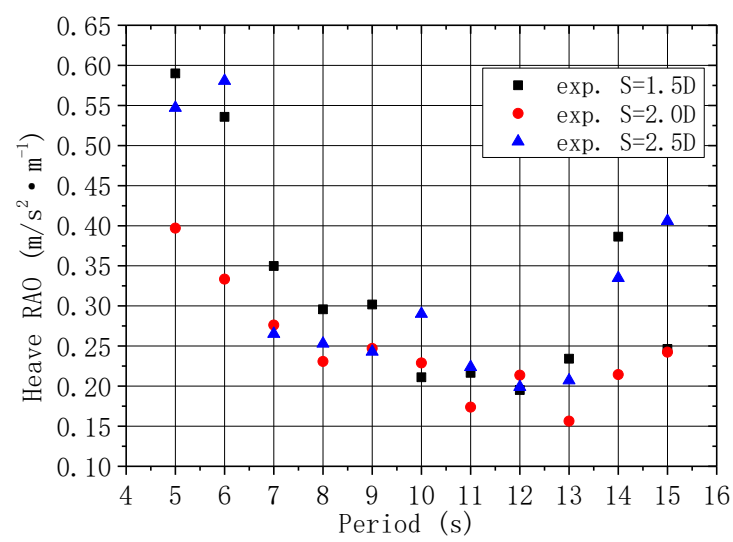

(a)

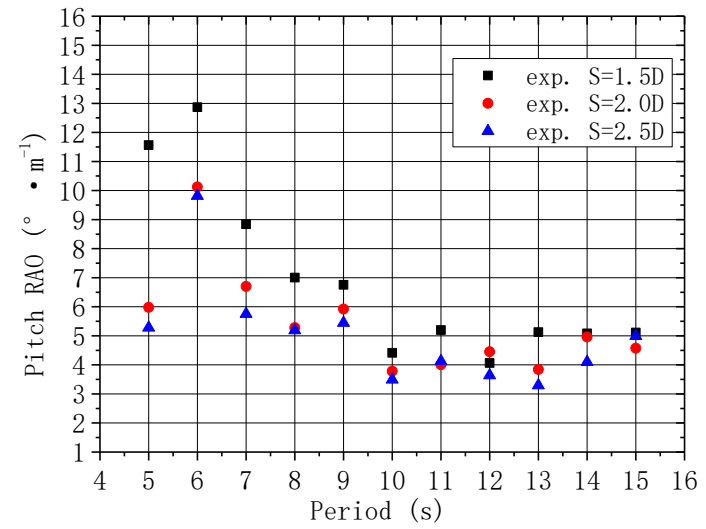

(b)

Figure 16. Experimental RAOs at a $4.0 \mathrm{~m}$ draft with different bucket spacings: (a) heave RAO and (b) pitch RAO.

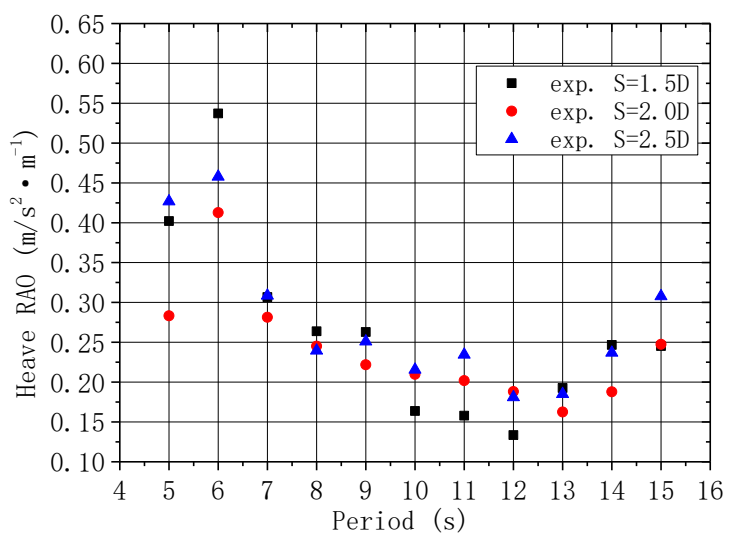

(a)

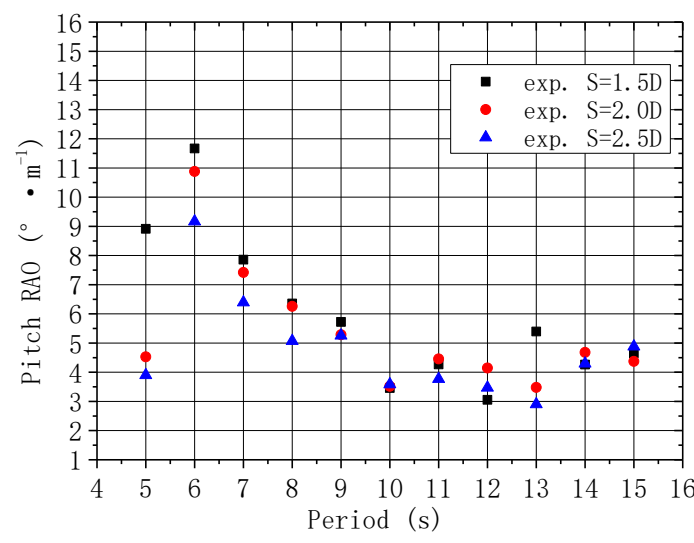

(b)

Figure 17. Experimental RAOs at a $4.5 \mathrm{~m}$ draft with different bucket spacings: (a) heave RAO and (b) pitch RAO.

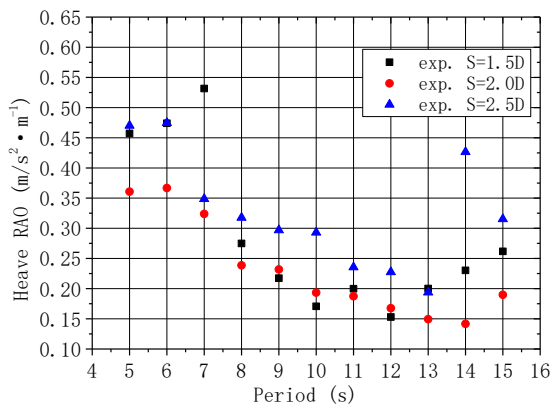

(a)

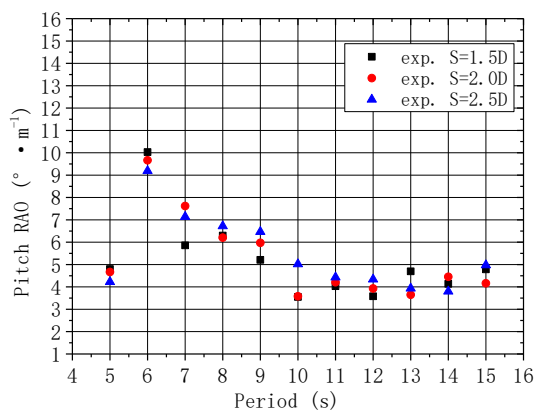

(b)

Figure 18. Experimental RAOs at a $5.0 \mathrm{~m}$ draft with different bucket spacings: (a) heave RAO and (b) pitch RAO. 
The RAOs of heave motion and pitch motion with different bucket spacings at a $4.0 \mathrm{~m}$ draft ata water depth of $12.5 \mathrm{~m}$ are shown in Figure 16. In Figure 16a, the maximum amplitudes of heave acceleration $0.461 \mathrm{~m} / \mathrm{s}^{2}$ for $\mathrm{S}=1.5 \mathrm{D}, 0.415 \mathrm{~m} / \mathrm{s}^{2}$ for $\mathrm{S}=2.0 \mathrm{D}$, and $0.457 \mathrm{~m} / \mathrm{s}^{2}$ for $\mathrm{S}=2.0 \mathrm{D}$ occurred near the period of $5 \mathrm{~s}, 5 \mathrm{~s}$, and $6 \mathrm{~s}$, respectively. Other amplitudes of heave acceleration for $\mathrm{S}=1.5 \mathrm{D}$ and $\mathrm{S}=2.5 \mathrm{D}$ are $0.386 \mathrm{~m} / \mathrm{s}^{2}$ at a period of $14 \mathrm{~s}$ and $0.406 \mathrm{~m} / \mathrm{s}^{2}$ at a period of $15 \mathrm{~s}$, respectively, while the responses of heave acceleration for $\mathrm{S}=2.0 \mathrm{D}$ are almost the smallest in all the periods than those of $S=1.5 \mathrm{D}$ and $\mathrm{S}=2.5 \mathrm{D}$. As shown in Figure 16b, the pitch RAOs decreased with the increase in $\mathrm{S}$. This can be attributed to a larger moment of inertia with wider spacing. However, the maximum values of the pitch angle are $12.87^{\circ}, 10.12^{\circ}$, and $9.82^{\circ}$, respectively. With increasing $\mathrm{S}$ from $1.5 \mathrm{D}$ to $2.0 \mathrm{D}$, the maximum amplitude decreased by $2.75^{\circ}$, while this amplitude only decreased by $0.3^{\circ}$ when $\mathrm{S}$ increased from $2.0 \mathrm{D}$ to $2.5 \mathrm{D}$. This indicates that simply improving the pitch RAOs by increasing the spacing between bucket foundations is limited. This cannot satisfy the requirements of low cost and high efficiency development for offshore wind power, while a larger spacing results in increasing material consumption of connecting members and the cost.

The RAOs of heave motion and pitch motion with different bucket spacings at $4.5 \mathrm{~m}$ draft in a water depth of $12.5 \mathrm{~m}$ are shown in Figure 17. The maximum amplitudes of heave acceleration for $\mathrm{S}=2.0 \mathrm{D}$ are less than those of $\mathrm{S}=1.5 \mathrm{D}$ and $\mathrm{S}=2.5 \mathrm{D}$ around the resonant period. The heave RAOs with a wider spacing were slightly larger than those with a narrower spacing with the period longer than $7 \mathrm{~s}$. Figure $17 \mathrm{~b}$ shows that the pitch RAOs have a similar decreasing trend as the $4.0 \mathrm{~m}$ draft with the increase in s. The maximum amplitudes of pitch angle, smaller than the amplitudes at $4.0 \mathrm{~m}$ draft, are $11.67^{\circ}$ for $\mathrm{S}=1.5 \mathrm{D}, 10.88^{\circ}$ for $\mathrm{S}=2.0 \mathrm{D}$, and $9.17^{\circ}$ for $\mathrm{S}=2.5 \mathrm{D}$.

The RAOs of heave motion and pitch motion with different bucket spacings at $5.0 \mathrm{~m}$ draft at the water depth of $12.5 \mathrm{~m}$ are shown in Figure 18. Figure 18a shows that the maximum amplitudes of heave acceleration $0.532 \mathrm{~m} / \mathrm{s}^{2}$ for $\mathrm{S}=1.5 \mathrm{D}, 0.367 \mathrm{~m} / \mathrm{s}^{2}$ for $\mathrm{S}=2.0 \mathrm{D}$, and $0.475 \mathrm{~m} / \mathrm{s}^{2}$ for $\mathrm{S}=2.0 \mathrm{D}$ occurred near the period of $7 \mathrm{~s}, 6 \mathrm{~s}$, and $6 \mathrm{~s}$, respectively. The heave RAOs with a wider spacing were larger than those with a narrower spacing when the periods were longer than $7 \mathrm{~s}$. As shown in Figure 18b, the maximum amplitudes of pitch angle, smaller than the amplitudes at $4.0 \mathrm{~m}$ and $4.5 \mathrm{~m}$ $\mathrm{draft}$, are $10.03^{\circ}$ for $\mathrm{S}=1.5 \mathrm{D}, 9.66^{\circ}$ for $\mathrm{S}=2.0 \mathrm{D}$, and $9.19^{\circ}$ for $\mathrm{S}=2.5 \mathrm{D}$. However, the pitch RAOs increase with the increase in spacing between bucket foundations, and the variation trend is contrary to the trend at a $4.0 \mathrm{~m}$ draft and a $4.5 \mathrm{~m}$ draft. The heave RAOs for $\mathrm{S}=2.5 \mathrm{D}$ were much larger than those for $S=1.5 \mathrm{D}$ and $\mathrm{S}=2.0 \mathrm{D}$ in almost each period, i.e., the wider the spacing between bucket foundations, the larger the heave RAOs. Therefore, simply improving the pitch RAOs by increasing the spacing between bucket foundations is limited and negatively affects the motion performance during the transportation of LDTBF.

\section{Conclusions}

In this paper, the motion responses of LDTBFs supported by an air cushion and a water plug in each bucket foundation were evaluated through a series of laboratory tests (on 1/25 scale) and verified by the models established using the hydrodynamics software MOSES. A comparison between the experimental and simulated results indicates that the presence of an air cushion in the bucket foundation reduces the responses of structures and the technique of air floating transportation for LDTBF can be applied to engineering practices. The effects of three features, draft, water depth, and bucket spacing on LDTBF were evaluated. In this context, the main conclusions of the study are as follows:

(1) The resonant period for heaving motion increases with an increasing draft.

(2) The maximum amplitude for heaving and pitching motions decrease with the increase of draft for $S=1.5 \mathrm{D}$ and $\mathrm{S}=2.5 \mathrm{D}$, but, first increase and then decrease with an increasing draft for $\mathrm{S}=2.0 \mathrm{D}$.

(3) The resonant period for heaving motion increases with an increasing water depth.

(4) The maximum amplitude for heaving and pitching motions first decrease and then increase with the increase of water depth. 
(5) The maximum amplitude for heaving motion first decreases and then increases with increasing bucket spacing; futhermore, the wider the spacing between bucket foundation, the lower the heaving resonant period.

(6) The pitch RAOs decrease with the increase of spacing between the bucket foundations; however, the wider the spacing between the bucket foundations, the larger the heave RAOs.

(7) The optimal motion responses for LDTBFs are achieved at a $4.5 \mathrm{~m}$ draft and a $11.25 \mathrm{~m}$ water depth when the spacing between the bucket foundations is 2.0D.

Author Contributions: Formal analysis, X.L.; Funding acquisition, H.D.; Methodology, X.L. and P.Z.; Project administration, H.D.; Supervision, M.Z.; Validation, C.L.; Writing—original draft, X.L.; Writing—review \& editing, P.Z.

Funding: The author would like to acknowledge the support by the National Natural Science Foundation of China (Grant No. 51679163), Chongqing Municipal Natural Science Foundation (Grant No. CSTC2016JCYJA0580), and State Key Laboratory of Hydraulic Engineering Simulation and Safety (Tianjin University) (Grant No. HESS-12).

Conflicts of Interest: The authors declare no conflicts of interest.

\section{References}

1. Wang, X.; Zeng, X.; Li, X.; Li, J. Investigation on offshore wind turbine with an innovative hybrid monopile foundation: An experimental based study. Renew. Energy 2019, 132, 129-141. [CrossRef]

2. Andersen, P. Ship Motion and Sea Loads in Restricted Water Depth; Report No. 148; Danish Center for Applied Mathematics and Mechanics: Lyngby, Denmark, 1978.

3. Bie, S.A.; Ji, C.N.; Ren, Z.J.; Li, Z.Z. Study on floating properties and stability of air floated structures. China Ocean Eng. 2002, 16, 263-272.

4. Byrne, B.W.; Houlsby, G.T.; Martin, C.; Fish, P. Suction caisson foundations for offshore wind turbines. Wind Eng. 2002, 26, 145-155. [CrossRef]

5. Chenu, B.; Morris-Thomas, M.T.; Thiagarajan, K.P. Some hydrodynamic characteristics of an air-cushion supported concrete gravity structure. In Proceedings of the 15th Australasian Fluid Mechanics Conference, Sydney, Australia, 13-17 December 2004.

6. Ding, H.; Hu, R.; Le, C.; Zhang, P. Towing Operation Methods of Offshore Integrated Meteorological Mast for Offshore Wind Farms. J. Mar. Sci. Eng. 2019, 7, 100. [CrossRef]

7. Ding, H.; Liu, Y.; Zhang, P.; Le, C. Model tests on the bearing capacity of wide-shallow composite bucket foundations for offshore wind turbines in clay. Ocean Eng. 2015, 103, 114-122. [CrossRef]

8. Faltinsen, O.M. Sea Loads on Ships and Offshore Structures; Cambridge University Press: London, UK, 1990.

9. Fu, D.F.; Bienen, B.; Gaudin, C.; Cassidy, M. Undrained capacity of a hybrid subsea skirted mat with caissons under combined loading. Can. Geotech. J. 2014, 51, 934-949. [CrossRef]

10. Ghani, P.; Julait, J. Prediction of added resistance of ship due to regular head waves. J. Mek. 2008, 26, 1-8.

11. Guéret, R.; Hermans, A.J. Air cushion under floating offshore structure. In Proceedings of the Sixth International Workshop on Water Waves and Floating Bodies, Hiroshima, Japan, 22-25 April 2001; pp. 45-49.

12. van Kessel, J.L.F.; Pinkster, J.A. The effect of aircushion division on the structural loads of large floating offshore structures. In Proceedings of the 26th International Conference on Offshore Mechanics and Arctic Engineering, ASME, San Diego, CA, USA, 10-15 June 2007.

13. van Kessel, J.L.F.; Pinkster, J.A. Wave-induced structural loads on different types of aircushion supported structures. In Proceedings of the 17th International Offshore and Polar Engineering Conference, Lisbon, Portugal, 1-6 July 2007.

14. van Kessel, J.L.F. Aircushion Supported Mega-Floaters. Ph.D. Thesis, Delft University of Technology, Delft, The Netherlands, 2010.

15. Houlsby, G.T.; Ibsen, L.B.; Byrne, B.W. Suction Caissons for Wind Turbines; Frontiers in Offshore Geotechnics: Perth, WA, Australia, 2005; pp. 75-93.

16. Hill, A.B.; Ronalds, B.F. Optimised float-out of concrete offshore platform towards increasing construction potential in Australia. In Proceedings of the SPE Asia Pacific Oil \&Gas Conference, Perth, Australia, 12-14 October 1998. 
17. Lars, B.I. The bucket foundation and its competitiveness versus monopiles and jacket structures. In Proceedings of the International Conference in Research at Alpha Ventus, Bremerhaven, Germany, 9-10 May 2012.

18. Le, C.H.; Ding, H.Y.; Zhang, P.Y. Air-floating towing behaviors of multi-bucket foundation platform. China Ocean Eng. 2013, 27, 645-658. [CrossRef]

19. Hung, L.C.; Kim, S.-R. Evaluation of combined horizontal-moment bearing capacities of tripod bucket foundations in undrained clay. Ocean Eng. 2014, 85, 100-109. [CrossRef]

20. Liu, J.H. Investigation on Towing Behaviour of Bucket Foundation Ocean Platform with Air Cushion. Ph.D. Thesis, Tianjin University, Tianjin, China, 2008.

21. Malenica, S.; Zalar, M. An alternative method for linear hydrodynamics of air cushion supported floating bodies. In Proceedings of the 15th International Workshop on Water Waves and Floating Bodies, Caesarea, Israel, 17 February-1 March 2000; pp. 1-4.

22. MOSES. Reference Manual for Moses; Ultramarine Inc.: Houston, TX, USA, 2009.

23. Pinkster, J.A.; Fauzi, A. Motions and drift forces of air-supported structures in waves. In Proceedings of the Fifth Workshop on Nonlinear Wave Action on Structures and Ships, La Garde, France, 4 September 1998.

24. Pinkster, J.A.; Fauzi, A.; Inoue, Y.; Tabeta, S. The behavior of large air cushion supported structures in waves. In Proceedings of the Hydroelasticity in Marine Technology, Fukuoka, Japan, 1-3 December 1998; pp. 497-506.

25. Pinkster, J.A.; Meevers Scholte, E.J.A. The behavior of a large air-supported MOB at sea. Mar. Struct. 2001, 14, 163-179. [CrossRef]

26. Qi, X.Y. Experimental Study on Behaviour of an Open Bottom Floating Platform in Wave, Wind and Current. In Proceedings of the International Offshore and Polar Engineering Conference, Osaka, Japan, 10-15 April 1994.

27. Seidl, L.H. Development of an Air Stabilized Platform; University of Hawaii, Department of Ocean Engineering Technical Report Submitted to US Department of Commerce, Maritime Administration; University of Hawaii: Honolulu, HI, USA, 1988.

28. Seonguk, S.; Sunho, P.; BonYong, K. Effect of wave periods on added resistance and motions of a ship in head sea simulations. Ocean Eng. 2017, 137, 309-327.

29. Tabeta, S. Model Experiments on Barge Type Floating Structures Supported by Air Cushions; Ship Hydromechanics Laboratory Report; Delft University of Technology: Delft, The Netherlands, 1998; p. 1125.

30. Thiagarajan, K.P. Hydrostatic stability of compartmented structures supported by air cushions. J. Ship Res. 2009, 53, 151-158.

31. Thiagarajan, K.P.; Morison-Thomas, M.T. Wave-induced motions of an air cushion structure in shallow water. Ocean Eng. 2006, 33, 1143-1160. [CrossRef]

32. Thiagarajan, K.P.; Morris-Thomas, M.T.; Spargo, A. Heave and pitch response of an offshore platform with air cushion support in shallow water. In Proceedings of the 23rd International Conference Offshore Mechanic and Arctic Engineering, Vancouver, BC, Canada, 20-25 June 2004; pp. 1-7.

33. Thiagarajan, K.; Sow, H.E.; Ronalds, B.; Hill, A.B. Vertical motions of a concrete gravity structure supported by air cushion in shallow water. In Proceedings of the Offshore Mechanics and Arctic Eng., New Orleans, LA, USA, 14-17 February 2000; pp. 1-7.

34. Wu, X.H.; Zhang, L.W.; Wang, R.K. Ship Manoeuvring and Seakeeping; China Communication Press: Beijing, China, 1988.

35. Zhang, P.Y.; Ding, H.Y.; Le, C.H.; Huang, X. Motion analysis on integrated transportation technique for offshore wind turbines. J. Renew. Sustain. Energy 2013, 5, 053117. [CrossRef]

36. Zhang, P.Y.; Han, Y.Q.; Ding, H.Y.; Zhang, S.Y. Field experiments on wet tows of an integrated transportation and installation vessel with two bucket foundations for offshore wind turbines. Ocean Eng. 2015, 108, 769-777. [CrossRef]

(C) 2019 by the authors. Licensee MDPI, Basel, Switzerland. This article is an open access article distributed under the terms and conditions of the Creative Commons Attribution (CC BY) license (http://creativecommons.org/licenses/by/4.0/). 